\title{
INTERTEXTOS Y MEMORIA EN JUANA DE MANUELA INFANTE*
}

\author{
Eduardo Thomas Dublé \\ Universidad de Chile
}

RESUMEN/ABSTRACT

La obra de Manuela Infante es una de las más interesantes del teatro chileno emergente de la última década, por su contenido autorreflexivo y amplio espectro de alusiones culturales. En su pieza Juana (2004) destacan las referencias a obras de Vicente Huidobro, Rodolfo Usigli y Bernard Shaw, que vinculan la concepción dramática de esta joven dramaturga chilena con los postulados estéticos y filosóficos de estos autores, en los que convergen arte, mito y memoria. Se estudiará la reelaboración de la figura de Juana de Arco en la obra mencionada a la luz de estos intertextos, para demostrar que el "trabajo de la memoria" histórica que realizan Infante y la Compañía Teatro de Chile, tiene fundamentos en una sólida tradición latinoamericana y europea.

PALABRAS ClAVE: Manuela Infante, poética teatral, intertextualidad, memoria.

The plays of Manuela Infante may be considered some of the most interesting works when we study the new Chilean drama of the last decade, both because of their introspective contents and because of the wide range of cultural allusions to be found in her plays. In her piece Juana (2004), we find significant references to the works of Vicente Huidobro, Rodolfo Usigli and Georges Bernard Shaw, thus establishing a relationship between the dramatic conceptions of this young Chilean playwright and the philosophical and esthetic tenets of those authors: there we may find a convergence of art, myth and memory. In this essay we will study the reworking of the character of Joan of Arc in the already mentioned play Juana, and we

${ }^{*}$ Trabajo leído en el Primer Seminario Internacional: Teatro, Historia, Memoria, el 21 de octubre de 2008 en la Escuela de Teatro de la Pontificia Universidad Católica de Chile. Evento organizado por esa Escuela, el Centro de Investigación Teatral Teatro la Memoria y la Facultad de Artes de la Universidad Mayor, entre los días 21 y 23 de octubre de ese año. 
will explore the importance of these intertexts in order to show that the 'works of historical memory' to be found in Infante and the Compañia Teatro Club is founded on a solid Latin American and European tradition.

KEY WORKS: Manuela Infante, Dramatical poetics, intertextuality, memory.

En la producción dramatúrgica de Manuela Infante y su grupo Compañia Teatro de Chile, la temática histórica tiene un lugar destacado. Sus obras más conocidas desarrollan una reflexión sobre la memoria cultural, sus posibilidades de representación artística, sus relaciones con el poder y la situación del teatro ante estos temas. En esta línea se encuentran los textos publicados por la editorial Ciertopez: la polémica Prat (2002), obra inicial del grupo, y Juana (2004), que le siguió (Infante). La última obra de la Compañía, Cristo (2008), sintetiza los contenidos temáticos y establece un nuevo hito en la búsqueda estética, metodológica y epistemológica desarrollada en los dos textos mencionados, a los que tal vez habría que sumar Rey planta (2006), que también incorpora temas sobre memoria, representación y poder ${ }^{1}$.

El Prólogo de la Compañía Teatro de Chile a la edición mencionada de Prat y Juana, titulado "Como un juego de puntos que se unen", explica que la representación de las figuras históricas de Arturo Prat y Juana de Arco en esas obras se justifica "como un modo de revelar el mecanismo de la interpretación y el rol que juega en nuestro aprehender y conocer el mundo y la historia" (Infante 9). Se trata, por lo tanto, de una poética teatral que considera al arte como un instrumento de reflexión crítica sobre los relatos sustentados por los discursos sociales, en especial el de la Historia.

La representación de Arturo Prat en la obra mencionada ejemplifica su modo de elaborar a las figuras históricas para someterlas a un proceso de resemantización. El ya citado prólogo de la Compañía Teatro de Chile explica la estrategia discursiva de Infante para lograr este efecto renovador: “(...) bastó con imaginar a un Prat diferente del oficial: un adolescente de 16 años

Otras obras de su producción: Narciso (2005) y la reciente Fin (2008), escrita y producida en Viterbo, Italia, sobre un texto de Alejandro Moreno. Con posterioridad a la lectura de este trabajo, la Compañía estrenó Ernesto en el mes de enero de 2010 en el marco del programa "Teatro a Mil" correspondiente a este año. Importa destacar que en este caso la imagen social sometida a crítica es el texto de una obra fundacional del teatro chileno, representativa del Movimiento Literario de 1842. 
que tiene miedo de estar donde está, uno que preferiría los brazos de su madre o el calor de la amistad en tiempos de paz, para que se levantara la polémica, aun cuando Prat estuviera incompleto, pues aún no había sido estrenado" (10). El recurso descrito por la Compañía de Chile recuerda los mecanismos definidos por Paul Ricoeur en su teoría del lenguaje simbólico (Ricoeur, Teoría). La yuxtaposición de la imagen de un niño desvalido y angustiado con la del capitán heroico, opera como una "metáfora radical" que obliga al lector/espectador a reinterpretar el arquetipo del héroe épico, símbolo ancestral sobre el que está construida la figura del héroe de Iquique. El proceso de reinterpretación conduce al lector/espectador a comprender a Arturo Prat desde una perspectiva inédita: "como si..." fuera un niño angustiado por el desamparo. Esta actividad reinterpretativa, finalmente, crea un nuevo sentido que resuelve la impertinencia lógica del texto, estableciendo una perspectiva renovadora sobre el arquetipo heroico. Este nuevo héroe enfrenta el sacrificio consciente de su propio abandono; siente flaquear sus fuerzas ante el absurdo de la muerte; no niega su nostalgia del amor en un mundo del cual la Madre -fuente original del sentido- se ha ausentado.

La propia Manuela Infante explica la estrategia discursiva que estoy comentando. En el texto titulado "Figura y fondo", incorporado como "post scriptum" a la edición de Prat y de Juana citada anteriormente, compara su representación del pasado con el juego de las figuras de cartón a las que se les deja un agujero por el cual las personas asoman su rostro en los parques de diversión (Infante 120) ${ }^{2}$. En esta imagen propuesta por la dramaturga, el pasado histórico es simbolizado por la figura de cartón; y el presente, por los clientes de la feria que asoman su rostro por el agujero de la figura. En sus textos, prosigue Infante, el presente asoma su rostro por los agujeros del relato histórico, obligando al lector/espectador a reinterpretar el pasado y descubrir su riqueza silenciada por el discurso histórico oficial vigente. Son obras que, como todo arte de tema histórico, desean referirse al mundo actual: "He escrito entonces unos textos sobre el pasado lleno de agujeros para ver si el presente ponía su rostro y se hacía figura. Para ver si de algún modo se confesaba" (120).

En Juana, las estrategias para elaborar artísticamente la figura de la heroína son semejantes a las que operaron en la obra anterior sobre Prat. El

2 La metáfora de la figura de cartón la desarrolló intensamente, cuatro años después, en la escenificación de Cristo. 
personaje de Juana de Arco se construye como una adolescente campesina, encantadoramente infantil, motivada por su fe absoluta en las voces que solo ella escucha y le están comunicando su misión como agente terreno de una acción divina destinada a salvar a Francia. Este tratamiento de Juana de Arco refiere a una tradición dramatúrgica que se remonta a Bernard Shaw, por su semejanza con el modelo femenino que el gran dramaturgo irlandés estableció en su Santa Juana (1923). La construcción del relato dramático de Juana se ciñe en parte a la del texto de Bernard Shaw, simplificándolo para acentuar el tono infantil de la representación y reduciendo al mínimo los acontecimientos del juicio y condena de la heroína, a los que sintetiza en un monólogo, que solo sugiere su desesperada lucidez final ante la muerte. La obra del autor irlandés, en cambio, destina la larga Escena Sexta al juicio y condena de Juana por la Inquisición, acontecimientos en los que condensa su irónico escepticismo. La referencia a Bernard Shaw es explícita en el texto de Manuela Infante, en citas que son fundamentales para su interpretación de la heroína francesa.

Una de esas citas remite al diálogo en que Juana informa al capitán Roberto de Baudricourt ${ }^{3}$ sobre las voces que escucha y la misión que éstas le encomiendan. El texto de Infante reproduce literalmente el fragmento de la obra de Bernard Shaw:

"JUANA: Oigo voces que me dicen lo que hay que hacer. Vienen de Dios.

BRADRICOURT: Vienen de vuestra imaginación.

JUANA: Claro, así es como las órdenes de Dios llegan a nuestro conocimiento" (Infante 76; Shaw 28).

En la obra de Bernard Shaw, Juana de Arco reitera muchas veces esta misma idea, con distintos matices, tratando de convencer, tanto a los representantes de la nobleza como a los del clero, sobre la importancia de escuchar esas voces, que nos hablan a todos, pero que muy pocos atienden. De acuerdo con la interpretación del dramaturgo irlandés, la fidelidad de la heroína a sus voces la indispuso con las instituciones políticas y eclesiásticas, pues establecía una relación directa con Dios, saltándose a las autoridades de la Monarquía y la Iglesia. Su enorme popularidad amenazaba a los dos poderes.

3 En el texto de Infante el personaje se nomina "Bradricourt", seguramente como un índice de su resemantización. 
Con esta cita, la obra de Infante acoge el valor que el texto de Bernard Shaw concede a la imaginación como fuente y fundamento de verdad existencial: "las voces llegan primero, y las razones las encuentro después", explica Juana a Dunois en la Escena Quinta de Santa Juana (Shaw). La heroína, en el mismo diálogo, le confidencia a este personaje que cuando escucha las campanadas de la catedral en una situación de recogimiento (desde el campo, o en la soledad de un rincón del templo), las voces divinas le hablan en su tañido.

Contrasta en la obra de Bernard Shaw esta experiencia estética, ingenua y pura, que conduce a la adolescente campesina al descubrimiento de la fe en la música de las campanas de la iglesia, con el nada inocente montaje que organizan en la Corte, con fines políticos, para que Juana opere el "milagro" de reconocer al Delfín. Aparece este episodio como una escenificación teatral, en la que los interesados promotores del artificio también participan como actores. Juana reconoce al Delfín sin dificultad alguna y confirma su prestigio popular de santa milagrosa, pero esta vez su milagro es producto de la manipulación de los mismos poderes que más tarde, cuando vean en ella una amenaza, terminarán por condenarla a la hoguera. Sin embargo, todo en Santa Juana parece indicar que, efectivamente, está ocurriendo un milagro. Como lo afirma Poulengey a Roberto Baudricourt, el verdadero milagro es la propia doncella:

"ROBERTO: ¡Cómo! ¿Crees que la rapaza puede obrar milagros? POULENGEY: Creo que la muchacha misma es un milagro" (23).

Se comprende esta aseveración de Poulengey, a la luz de otro fragmento textual de la obra de Bernard Shaw que Manuela Infante incorpora literalmente en Juana. Se trata de la definición de "milagro" que formula el Arzobispo de Reims al señor de La Tremouille:

"ARZOBISPO: Un milagro, amigo mío, es un suceso que crea fe. Ese es el propósito y la índole de los milagros. Podrán parecer muy maravillosos a los que los presencian, pero son muy sencillos para los que los hacen. No importa; con tal de que confirmen o creen la fe, son verdaderos milagros.

LA TRÉMOUILLE: ¿Aunque sean embustes?

ARZOBISPO: Los embustes engañan. Pero un suceso que crea fe no engaña; por eso no es un embuste, sino milagro" (Shaw 48-9; Infante 79-80). 
Este diálogo es incorporado como epígrafe por el dramaturgo mexicano Rodolfo Usigli en una de sus obras fundamentales: Corona de luz. La Virgen. (1963). Recoge Usigli el concepto de milagro como un suceso que crea fe, y lo aplica a la reinterpretación del mito mexicano de la Virgen de Guadalupe. Así como en la obra de Bernard Shaw la leyenda de Juana de Arco nace de un montaje teatral cortesano que "crea fe" popular y, finalmente, se escapa de las manos de los poderosos para consolidarse como mito fundacional de la nación francesa, del mismo modo Rodolfo Usigli reformula el relato oficial de la aparición de la Virgen de Guadalupe, presentándolo como un montaje gestado por los diversos intereses políticos del México colonial, que termina por trascender este origen para establecerse en la fe popular como imagen identitaria de la nueva nación mestiza, consolidando la independencia cultural de México.

Rodolfo Usigli adopta de Bernard Shaw este modo de reelaborar el relato histórico por medio de la reinterpretación de los mitos nacionales, para fundamentar y llevar a la práctica su concepción poética del teatro como "comunión" 4 . Para él, el teatro, cuando realiza plenamente su potencialidad artística, constituye un ritual comparable a la misa católica: sus participantes (grupo artístico y público) se encuentran espiritualmente en el redescubrimiento de los símbolos culturales identitarios. En sus tres "Coronas", Rodolfo Usigli somete a procesos de resemantización a los tres mitos que él concibe como fundacionales de la nacionalidad mexicana: en Corona de luz. La Virgen, lo hace con la Virgen de Guadalupe; en Corona de sombra (1943) con Maximiliano y Carlota; y en Corona de fuego (1961), con la figura de Cuahutémoc ${ }^{5}$. En su obra más conocida y celebrada, El

4 Concepción que expone en el "Primer Prólogo" a Corona de luz.: "Todo espectador teatral, como todo feligrés, participa, y participa activamente hasta sacrificar su cuerpo en olvido de la fatiga y hasta aplaudir para subrayar esa ilusión de realidad, ese estado particular de arrebato, de desprendimiento de sí mismo en que ha pasado dos horas y media sentado en una mala butaca, cuando la pieza que ha presenciado tiene ese sentido religioso, único, que puede suscitar la comunión. (Esto ocurre en los toros). Y dondequiera que hay comunión hay sacrificio ritual, hay, en una sencilla palabra, misa" (Usigli 14). Sobre su poética: Luzuriaga y Thomas.

"Y debo indicar, señalando la actualidad permanente del problema guadalupano, la necesidad de obras teatrales que, por su religiosidad en el sentido extraeclesiástico de la palabra, hagan reaparecer el sentido y el sentimiento de la comunión del público, la intención de fondo de mis obras antihistóricas, hechas en sacrificio a tres mitos que considero superlativos: el mito 
gesticulador (1947), es el mito de la Revolución Mexicana el sometido a semejante procedimiento.

Bernard Shaw representa la historia de Juana de Arco explicitando los mecanismos históricos que generaron su mito y, en consecuencia, degradándolo, para luego reformularlo como un milagro radicado en la fe que la heroína protagonizó y creó; Usigli se apropia de este procedimiento $\mathrm{y}$, basándose en él, concibe como misión del teatro pensar y revitalizar el imaginario de la cultura nacional. En Corona de luz desmitifica la historia del milagro de la aparición de la Virgen de Guadalupe, representándolo como un montaje teatral constitutivo de un fraude político, para finalmente reinterpretarlo a la luz de la fe que generó, como un milagro liberador y fundador de la nación mexicana, como explica al final de esta obra el obispo Juan de Zumárraga a fray Toribio Benavente:

"FRAY JUAN: No diremos nada, Benavente. Dejaremos que la orgullosa corona española piense que todo pasó como ella lo había dispuesto. Dejaremos que España crea que inventó el milagro (...) Veo de pronto a este pueblo coronado de luz, de fe. Veo que la fe corre ya por todo México como un río sin riberas. Ése es el milagro, hermano" (Usigli 222-3).

La particular elaboración de las figuras históricas en las obras de Manuela Infante, de acuerdo con todo lo expuesto, recoge conscientemente una tradición teatral que remonta a la teoría de Rodolfo Usigli y a la obra Santa Juana de Bernard Shaw. Lo que recoge Infante de estos modelos textuales es un modo de relacionar al arte con el imaginario de la memoria cultural, consistente en la desmitificación y resignificación de los sistemas simbólicos; y también una concepción del teatro como acontecimiento milagroso, generador de fe y libertad en el sujeto comunitario.

El texto de Juana hace referencia a otra obra dramática de principios del siglo XX, que opera como un tercer intertexto relevante. Se trata de Gilles de Raiz (1932), obra dramática de Vicente Huidobro. El protagonista es el mismo Mariscal de Francia que aparece en Santa Juana nominado directamente como "Barba Azul" y recibiendo de parte del Arzobispo la profecía de su fin en la horca condenado por la Inquisición. Tanto Bernard Shaw como Manuela 
Infante presentan a este personaje en los momentos de la gesta épica en que acompañó a Juana de Arco como parte importante de su comando militar. Se limitan a sugerir su inquietante leyenda. El poeta chileno, en cambio, presenta en su obra la figura legendaria de Gilles de Rais: el hombre que se alejó de las batallas para retirarse al castillo de Machecoul y entregarse a una vida de desenfreno sexual y criminal. Esta es la etapa que interesó a los surrealistas, por lo que sugiere de exploración en los límites del placer, del inconsciente y del mal (Schopf; Béhar). Vicente Huidobro enfatiza esta interpretación al cambiar su nombre de "Rais" a "Raiz", significando así su interés por la leyenda del hombre que transgredió y desafió todas las normas terrenales y celestiales para internarse en las inquietantes raíces del ser.

El epígrafe del inicio de Gilles de Raiz orienta respecto de la intención de Vicente Huidobro: "Literatura-Literatura-Archiliteratura". Le interesan la poesía y misterio del mito construido en torno a este personaje, al que reformula como símbolo del poeta. Parece indudable que Vicente Huidobro tuvo presente el texto de Bernard Shaw al escribir su Gilles de Raiz. Las figuras de los protagonistas y la construcción del relato histórico en ambas piezas dramáticas presentan puntos de contacto que así lo indican. Los dos protagonistas son sometidos a juicio y condenados por la Inquisición. La intención y tono con que Gilles de Rais enfrenta al tribunal en la obra de Huidobro, son semejantes a los de Juana de Arco en la de Bernard Shaw. También es una semejanza con la obra del maestro irlandés la inclusión del "Epílogo", en el que Gilles, igual que Juana de Arco en Santa Juana, en un ambiente onírico y atemporal asiste al juicio de la Historia y termina por celebrar su estatus triunfal como mito.

Tiene que haber interesado al poeta chileno el latente contenido creacionista de la interpretación de Juana de Arco propuesta por Bernard Shaw. Ese contenido es el que recoge en su obra teatral, en la que presenta a Juana de Arco visitando a Gilles de Raiz para revelarle que no murió en Rouen, porque su lugar en la hoguera lo ocupó otra mujer que se sacrificó para permitirle continuar su lucha por liberar a Francia. El noble la disuade, haciéndole ver que su existencia ahora es la del mito generado por su muerte; es en esa condición que ella va a derrotar al poder inglés y liberar a Francia. Su persona corporal ha muerto sin remedio desde el momento que se transfiguró en el mito. Nadie aceptaría otra versión de la historia. La relación que establece Huidobro entre Gilles de Raiz y Juana de Arco es la del creador con la criatura: el noble participó en la gesta y en la trama que originaron la leyenda de la heroína; y decide, con la visión profética del 
poeta y el poder que le da su condición de creador, su destino como símbolo fundacional de la nación francesa.

Manuela Infante actualiza esta concepción huidobriana en el siguiente diálogo del Arzobispo con un paje, en el que se refieren a Juana de Arco:

"PAJE: ¿La niña hace milagros?

ARZOBISPO: Nosotros hacemos de la niña un milagro, ¿entendéis...?

PAJE: Entonces el milagro vendría a ser la niña misma.

ARZOBISPO: El milagro es la niña misma.

PAJE: Pero... ¿y si no fuese realmente enviada por Dios?

ARZOBISPO: Eso no tiene importancia...” (79).

La intensa vinculación intertextual que ha sido objeto de esta exposición, instala la obra de Manuela Infante en una tradición teatral que se remonta a los principios del siglo XX y a grandes figuras de la dramaturgia hispanoamericana y universal. De esta tradición, la joven dramaturga chilena parece recoger una concepción del teatro como liturgia renovadora de los imaginarios culturales; como hecho milagroso, revelador y liberador, capaz de vitalizar la fe del sujeto comunitario en su capacidad de pertenecer a una cultura y de participar en su permanente recreación; como instrumento de reflexión sobre las estructuras de poder que disimulan los imaginarios sociales. En síntesis, parece proponer un modo saludablemente trasgresor, desacralizador y revitalizador, de relacionarse el arte con la memoria histórica de los pueblos.

Puede ser iluminador considerar esta poética desde la dialéctica entre ideología y utopía como funciones básicas del imaginario social, propuesta por Paul Ricoeur (“La ideología...").

Basándose en el ejemplo de las ceremonias conmemorativas con que las comunidades -cualquier comunidad-celebran los sucesos y personajes vinculados a sus orígenes, Ricoeur distingue en la ideología funciones integradoras de la comunidad en torno a cierta estructura de la memoria social. En el caso de estas ceremonias -afirma-, es evidente su papel de "difundir la convicción de que esos acontecimientos fundadores son constitutivos de la memoria social y, a través de ella, de la identidad misma de la comunidad" (354). Construyen una estructura simbólica de la memoria social, constituyéndola en objeto de creencia por parte de la colectividad, y 
estableciendo un imaginario estable y perdurable, sustentador de identidad comunitaria.

Esta función integradora de la sociedad en torno a un imaginario y una memoria comunes, que Ricoeur define como indispensable y positiva, es inseparable de otras que cumple la ideología, orientadas hacia el disimulo y la legitimación de las estructuras de poder vigentes:

"Partamos nuevamente de nuestro ejemplo, el de una comunidad que conmemora los acontecimientos que considera fundacionales de su existencia. Es difícil que el fervor de los orígenes se mantenga; muy pronto, la convención, la ritualización, la esquematización se mezclan con la creencia, contribuyendo así a una especie de domesticación del recuerdo. Parecería que la ideología sólo puede conservar su poder movilizador si se ocupa de justificar a la autoridad que permite a la comunidad expresarse como un gran individuo en la escena mundial. Esto se ve en la manera como la conmemoración se transmuta tan fácilmente en argumento estereotipo: afirmamos que está bien que seamos como somos. La ideología continúa degenerándose si se considera con qué simplificación a menudo grosera, y con qué esquematización a menudo arrogante, se prolonga el proceso de integración en el de legitimación. Poco a poco, la ideología se convierte en una clave de lectura artificial y autoritaria no sólo de la manera de vivir del grupo, sino también de su lugar en la historia del mundo" (355).

Frente a esta función preservadora y conservadora de la realidad identitaria del grupo, desempeñada por la ideología, Ricoeur concibe a la utopía con un papel social diametralmente opuesto, consistente en el cuestionamiento del orden preservado por la ideología y la liberación de las energías creadoras reprimidas por aquél: "La utopía es un ejercicio de la imaginación para pensar en otro modo de ser de lo social" (357). La función esencial de la utopía es, siempre, "proponer una sociedad alternativa", "otro lugar", para cuestionar radicalmente la manera de ejercer el poder en cada una de las dimensiones y sectores de la sociedad actual. Al hacerlo, abre a nuestra existencia las posibilidades creadoras de la imaginación, impidiendo que la historia se anquilose en la pura repetición de la experiencia. Su crítica de las ideologías; su impugnación de los imaginarios y sistemas simbólicos; su proposición de "otro lugar radical", son imprescindibles en cualquier sociedad.

Reconociendo el carácter inevitablemente soñador, polémico y desestabilizador de la utopía ("En última instancia, es utópico todo aquello 
que, para los representantes de un orden dado, aparece a la vez como peligroso para ese orden e irrealizable en cualquier otro" (360), Paul Ricoeur concibe a la ideología y a la utopía como funciones complementarias en la cultura: la primera aporta estabilidad y cohesión a la comunidad; la segunda, libertad y vitalidad creadoras.

La concepción teatral de Manuela Infante y el Grupo Teatro de Chile se entiende bien a la luz de estos postulados de Paul Ricoeur sobre ideología y utopía. Su cuestionamiento y reinterpretación de los sistemas simbólicos que integran nuestra memoria colectiva cobran una significación vital y profunda al comprenderlos a partir de la interpretación del juego dialéctico entre estas dos funciones en los procesos culturales, que propone el hermeneuta francés. Sobre esta base, no es difícil entender la gran capacidad de remecer el ambiente cultural demostrada por la producción de esta dramaturga.

La intensa respuesta del público a sus montajes, sin embargo, pienso que no se origina solamente en su saludable cuestionamiento de las ideologías sustentadoras de nuestros imaginarios culturales. Espectadores y lectores percibimos en sus construcciones textuales la metáfora de una esperanzadora propuesta utópica.

En efecto, sus textos - escritos y espectaculares-, además de desconstruir los imaginarios simbólicos, se ofrecen como espacio abierto a la diversidad de discursos, de voces y perspectivas que integran a la sociedad; construyen un ámbito teatral propicio para el encuentro, diálogo y discusión entre la multiplicidad de perspectivas sobre lo real albergadas por nuestra memoria comunitaria, sin imponer jerarquía alguna; sin conceder privilegios ni siquiera a la voz de la dramaturga, que voluntariamente se fusiona con las de la Compañía de Chile y los personajes. Tomando como ejemplo los textos a que he hecho referencia en este trabajo, podría decir que todas las imágenes de Prat, de Juana de Arco y de Cristo encuentran su lugar en las obras correspondientes de este grupo, para articularse y dialogar.

El modo de producción de Cristo, que aparece destacado como uno de los contenidos temáticos centrales en esa obra, expresa esta concepción artística.

Ese modo no jerárquico, comunitario y dialogante, abierto, de producir y construir la obra teatral, es lo que percibo como un contenido utópico; una metáfora de la sociedad deseada. 


\section{BIBLIOGRAFÍA}

Béhar, Henri. "Vicente Huidobro y la cara del mal". Sobre el teatro dadá y surrealista, Barcelona, Editorial Barral. 1970. 206-209.

Huidobro, Vicente. Gilles de Raiz. En la luna. (Teatro completo). Santiago de Chile, Editorial Universitaria, 1995.

Infante, Manuela. Prat seguida de Juana. Santiago, Ciertopez, 2004.

Luzuriaga, Gerardo. "Rodolfo Usigli (México): En busca de la tragedia mexicana". Introducción a las teorías latinoamericanas del Teatro. De 1930 al presente. Universidad Autónoma de Puebla, 1990. 21-61.

Ricoeur, Paul. Teoría de la interpretación. Discurso y excedente de sentido. México: Siglo XXI Editores, 1995.

"La ideología y la utopía: dos expresiones del imaginario social". Del texto a la acción. México, Fondo de Cultura Económica, 2001. 349-360.

Schopf, Federico. "Nota sobre Gilles de Rais", estudio preliminar a Vicente Huidobro: Gilles de Raiz; En la luna (Teatro completo.) Santiago de Chile, Editorial Universitaria, 1995. IX -XIX.

Shaw, George Bernard. Santa Juana. Pigmalión. Santiago, Editorial Andrés Bello, 1984.

Thomas, Eduardo. "Teatro, símbolo y comunión: la poética de Rodolfo Usigli". Revista Chilena de Humanidades $\mathrm{N}^{\circ} 14$ (1993): 121-129.

Usigli, Rodolfo. Corona de luz. La Virgen. México: Fondo de Cultura Económica, 1965. 